\title{
Histórias em quadrinhos no ensino de ciências: um olhar sobre o que foi produzido nos últimos doze anos no ENEQ e ENPEC
}

Susan Caroline Camargo susancamargo@alunos.utfpr.edu.br orcid.org/0000-0002-5127-922X Universidade Tencnológica Federal do Paraná (UTFPR), Apucarana, Paraná, Brasil

Angélica Cristina Rivelini-Silva arivelini@utfpr.edu.br

orcid.org/0000-0003-1050-8003

Universidade Tencnológica Federal do Paraná (UTFPR), Apucarana, Paraná, Brasil

\begin{abstract}
RESUMO
Este artigo apresenta um levantamento bibliográfico de como as histórias em quadrinhos (HQs) são abordadas no contexto do ensino de ciências brasileiro. Partindo de uma pesquisa em dois dos principais eventos da área de ensino de ciências, os trabalhos obtidos foram divididos em categorias e agrupados de acordo com o foco principal de seus estudos. A maioria dos trabalhos que compõem nossa pesquisa bibliográfica possuem foco no uso de HQs enquanto materiais didáticos para o ensino de ciências no Ensino Fundamental e para o ensino de Química no Ensino Médio. Parte dos trabalhos obtidos se pautam nas contribuições de algumas revistas em quadrinhos ou manifestações desse gênero em livros didáticos. Uma pequena parcela dos artigos analisados discute sobre as HQs na formação docente. Nos últimos 5 anos houve um aumento significativo nas produções voltadas ao uso de HQs e sua contribuição no ensino de ciências. Os estudos que abordam o uso de materiais inéditos aparecem de maneira mais frequente quando comparados aqueles que se propõe a análise e/ou uso de materiais já disponíveis.
\end{abstract}

PALAVRAS-CHAVE: Histórias em quadrinhos. Ensino de ciências. Levantamento bibliográfico. 


\section{INTRODUÇÃO}

Um dos principais focos das pesquisas na área de Ensino de Ciências é a busca por novas teorias, metodologias e abordagens, que transformem a postura do docente em sala de aula, possibilitando assim que ele, com suas práticas, sobreponha principalmente as fortes características do ensino tradicional que prevalece nos currículos atuais.

Para Mizukami (1986) certas abordagens de ensino apresentam com nitidez um referencial filosófico e psicológico, onde a construção do conhecimento está condicionada as relações interpessoais do aluno, enquanto que outras são mais intuitivas, fundamentadas na prática ou na imitação de modelos, e focam-se em fatores externos aos estudantes. $O$ ensino tradicional de ciências é pautado em ações que se encaixam bem na segunda definição dada pela autora, já que propicia a formação de automatismos decorrentes da apresentação de conceitos aos alunos por meio de demonstrações teóricas, como produtos imutáveis, desconsiderando os processos que levaram a tal e que quase sempre tem como resultado, alunos que "aprenderam" apenas parcialmente o que deveriam.

Dentre as diversas ferramentas e estratégias possíveis de serem utilizadas para o ensino de ciências, nesse trabalho daremos ênfase as histórias em quadrinhos (HQs). Existe uma forte presença desse gênero textual em livros didáticos, desde aqueles voltados ao Ensino Fundamental aos utilizados no Ensino Médio. Seu uso se justifica, entre outras coisas, como uma "estratégia que proporciona flexibilidade e expansão de conceitos, permitindo relacionar ideias e formar novos conceitos a partir de signos e instrumentos da linguagem". (KAMEL; DE LA ROCQUE, 2011, p. 10).

Embora manifestações desse gênero tragam para as salas de aula um caráter mais lúdico, fazendo uso de uma linguagem mais informal combinada a elementos ilustrativos para apresentação de conceitos muitas vezes tidos como maçantes e de difícil compreensão e atuem como um meio de comunicação entre educador e educando, é necessário atentar-se para como as concepções de ciência e do "ser" cientista presentes nas histórias ou tiras em quadrinhos influenciam o modo como os alunos incorporam essas concepções em sua própria visão de mundo.

O objetivo desse trabalho, que compõe a pesquisa inicial de um trabalho de conclusão de curso, é trazer um panorama sobre como as histórias em quadrinhos (HQs) são abordadas no contexto do ensino de ciências brasileiro, em especial no ensino de química, avaliando o foco de alguns dos trabalhos já publicados sobre o assunto. Conhecer um pouco sobre a história das HQs contribuirá para discussões do levantamento, assim será apresentado a seguir um rápido histórico da constituição das HQs.

\section{BREVE CRONOLOGIA DAS HISTÓRIAS EM QUADRINHOS}

A necessidade de comunicar-se é algo intrínseco à natureza humana, que desde os primórdios, convivendo em "bandos" ou para fazer parte de um determinado grupo social, quis e precisou encontrar meios para exprimir seus sentimentos, relatar experiências ou mesmo passar instruções quando na condição de líder. São as gravuras, deixadas por nossos antepassados préhistóricos, que muitos estudiosos consideram ser a gênese da forma de 
comunicação que hoje conhecemos como histórias em quadrinhos, ou arte sequencial, de acordo com a definição de Eisner (1989).

Também semelhantes às histórias em quadrinhos tais como conhecemos, temos os pergaminhos do Egito Antigo. Esses documentos, que já combinavam elementos escritos, os chamados hieróglifos, e imagens, passavam quase sempre mensagens sobre como os deuses viam o homem e a civilização.

Há também a presença da arte sequencial na Idade Média, que em geral tinha a finalidade de narrar ao público com pouca educação formal, acontecimentos de cunho religioso, como se observa nos vitrais de grandes igrejas góticas.

Já no Renascimento, Lovetro (2011) destaca a Tapeçaria de Bayeux, um trabalho em bordado do século XII em comemoração à Batalha de Hastings, uma das mais importantes da história da Inglaterra que retrata os feitos de Guilherme I, o primeiro rei normando a governar a Inglaterra. A obra, de quase setenta metros de comprimento por meio metro de altura, incorpora textos aos desenhos nela representados, de forma que o autor a considera "uma verdadeira tira de quadrinhos gigante " (LOVETRO, 2011, p.11).

É com a prensa móvel de Johannes Gutenberg, no século XV, que as imagens impressas e os textos escritos propagam-se para a população (LOVETRO, 2011). Desse momento em diante os desenhos passaram a ser usados como uma ferramenta de liberdade de expressão, a exemplo das charges espalhadas em praças públicas e que satirizavam monarquias, criticavam sistemas políticos, reivindicavam direitos para o povo, entre outros.

Somente no século XIX, histórias começaram a ser de fato contadas por meio dos quadrinhos. De acordo com Moya (1986), a publicação da primeira história em quadrinhos com personagem fixo semanal ocorreu em 1985 no jornal americano World, publicado em Nova lorque. A história The Yellow Kid, criada por Richard Fenton Outcault, tinha como personagem principal um garoto de periferia, e inaugurou o uso dos balões de fala incorporados aos quadrinhos, impulsionando outros cartunistas a produzirem materiais nesse estilo.

Foi nesse mesmo século que as histórias em quadrinhos também surgiram no Brasil, que é considerado um precursor na elaboração e divulgação da linguagem moderna desses materiais. O destaque do país nesse âmbito, deu-se devido as contribuições dos trabalhos do artista gráfico ítalo-brasileiro Angelo Agostini, que ficou conhecido principalmente por sua obra As Aventuras de Nhô Quim, que retratava a viagem de Nhô Quim, um caipira que viaja de Minas Gerais para o Rio de Janeiro e sofre um choque de culturas ao se deparar com os costumes da vida urbana, trazidos pela corte portuguesa. A obra é considerada primeira história em quadrinhos brasileira e a primeira novela gráfica em capítulos do mundo, e foi publicada inicialmente na revista semanal de variedades e atualidades $A$ Vida Fluminense, da qual Agostini era editor.

No século passado, em especial nas décadas de 30 e 40, considerada a Era de Ouro das histórias em quadrinhos, elas passaram a desvincular-se dos jornais e revistas de variedades, para ganhar revistas próprias nos Estados Unidos, como as publicadas por Walt Disney. Durante a Segunda Guerra Mundial surgem os primeiros super-heróis, como o Capitão América, criado por Joe Simon com o intuito de entreter não só a população em geral, mas também os muitos soldados americanos que estavam em combate, passando uma forte mensagem de 
patriotismo. A primeira revista, foi publicada em 1941 pela editora Timely Comics, que mudou de nome e hoje é conhecida como Marvel Comics, uma das editoras mais famosas de histórias em quadrinhos de super-heróis.

Embora as histórias em quadrinhos americanas já estivessem sendo trazidas para o Brasil desde 1934 pela editora EBAL, influenciados pelo trabalho de Angelo Agostini, muitas outras histórias em quadrinhos nacionais surgiram. Em 1939, a editora O Globo lança a revista Gibi, que reunia vários contos na forma de quadrinhos e cujo nome foi emprestado de um dos personagens apresentados por ela. O sucesso da revista foi tão grande, que as histórias em quadrinhos no Brasil, passaram então a ser conhecidas como gibis, algo que prevalece ainda nos dias de hoje, onde inclusive nos dicionários, esses termos são reconhecidos como sinônimos (MOYA, 1986).

Atualmente, as histórias em quadrinhos nacionais que mais se destacam, foram as criadas na década de 60 por Ziraldo, com O Menino Maluquinho, e por Maurício de Sousa, com a Turma da Mônica, sendo que, esse último alcançou ao longo do tempo reconhecimento internacional, com o recebimento de diversos prêmios e o lançamento de publicações em diversos idiomas.

De fato, a arte sequencial esteve presente nas mais importantes épocas da civilização humana. Como consequência, as histórias em quadrinhos, caíram no gosto popular e, mesmo hoje, com a modernização e o avanço de tecnologias que possibilitaram desde animações para a TV e adaptações cinematográficas a revistas e quadrinhos inteiramente digitais, suas páginas continuam a cumprir o papel de entreter e alfabetizar pessoas de todas as idades no mundo todo, e é isso que as confere um grande potencial para serem utilizadas, também no ensino.

No que diz respeito ao ensino de ciências, que é o foco desse trabalho, destacam-se duas revistas em quadrinhos nacionais: a Sigma Pi, que trabalha conceitos de química, junto ao cotidiano dos personagens da trama, utilizando a estrutura dos mangás (revistas em quadrinhos japonesas), e a GIBIOzine, que atua na divulgação científica, principalmente de temáticas ambientais. Ambas as revistas são desenvolvidas por estudantes da Universidade Federal de São Carlos (UFSCar), e são citadas em alguns trabalhos que compõem o corpo de nossa pesquisa, como discutiremos mais à frente.

A seguir, apresentamos a metodologia utilizada para realização da pesquisa bibliográfica e os critérios de classificação.

\section{METODOLOGIA}

A realização dessa pesquisa de caráter bibliográfico foi realizada por meio de consultas em anais de dois eventos relevantes da área de Ensino de Ciências e de Química. Foram eles: o Encontro Nacional de Ensino de Química (ENEQ) e Encontro Nacional de Pesquisa em Educação em Ciências (ENPEC).

Os artigos analisados, foram obtidos a partir de consultas nos anais dos eventos já citados, disponíveis online nos respectivos sites. Os mesmos foram localizados utilizando-se na busca as seguintes palavras-chave: História em Quadrinhos, HQ e Super-heróis. Levou-se em conta para essa pesquisa todas as produções entre 2005 e 2016, resultando em 54 artigos que constituem esse estudo, sendo a maioria para o ensino de Química, mas com alguns voltados 
também ao ensino de Ciências, Biologia e Física. Todos os artigos encontrados, e que utilizaremos ao longo do desenvolvimento deste trabalho, encontram-se devidamente identificados na seção de referências bibliográficas.

Analisou-se principalmente o objetivo e a metodologia de cada artigo, além das considerações feitas pelos autores acerca dos principais resultados obtidos. Com a leitura desses pontos, percebeu-se que muitos artigos possuíam metodologia e objetivos similares, o que possibilitou que, para a análise, eles pudessem ser agrupados de acordo com o uso das HQs em seus respectivos estudos e divididos em 4 categorias distintas: Materiais didáticos (MD), para aqueles que traziam propostas de utilização de HQs como ferramentas em sala de aula; Análise das contribuições para o ensino (ACE), para aqueles que traziam análises do potencial didático e dos conceitos científicos presentes tanto em histórias em quadrinhos de livros didáticos quanto em revistas bastante populares do gênero, que funcionam como meios informais de divulgação da ciência; Formação de Docentes (FD), para os que discutiam as contribuições de oficinas e atividades nos cursos de formação inicial ou de formação continuada de docentes, que abordem produção e utilização das histórias em quadrinhos como ferramentas didáticas; e Pesquisa Bibliográfica (PB), para os artigos que buscavam discutir sobre os usos e contribuições das HQs no ensino, a partir da análise dos resultados de outras pesquisas já publicadas sobre o assunto. No Quadro 1 abaixo, consta o número de artigos foram encontrados por categoria em cada evento.

Quadro 1 - Relação de artigos encontrados nos anais dos eventos disponíveis online

\begin{tabular}{c|c|c|c|c} 
Eventos & MD & ACE & FD & PB \\
\hline \multirow{2}{*}{ ENEQ } & 22 & 2 & 1 & 1 \\
\hline \multirow{2}{*}{ ENPEC } & 20 & 5 & 2 & 1 \\
\hline
\end{tabular}

Para a discussão dos resultados, atribuiu-se um código a cada artigo, numerando-os de 1 a 54, respeitando-se a ordem com que apareceram nas buscas, de acordo com o ano de realização do evento em que foram publicados, e atribuindo-os a sigla de acordo com a categoria em que melhor se adequaram (MD, ACE, FD ou PB). Os artigos da categoria MD foram, ainda, agrupados de acordo com os níveis ou modalidades de ensino em que os trabalhos foram desenvolvidos ou se destinaram: Ensino Fundamental (EF), Ensino Médio (EM), Ensino Superior (ES) e Ensino Inclusivo (EI).

\section{RESULTADOS E DISCUSSÃO}

Dos artigos analisados, quarenta e dois se adequaram na categoria MD, demonstrando um grande interesse das produções na utilização de histórias em quadrinhos como ferramentas de apoio em sala de aula, seja para auxiliar na compreensão de um conceito já abordado ou para apresentar um novo conceito aos alunos.

Ainda nessa categoria, observou-se que metade dos artigos traziam como proposta a elaboração de uma história em quadrinhos por alunos a partir de um 
conceito previamente desenvolvido em sala. Nos artigos para o Ensino de Química, os principais conceitos abordados foram: tabela periódica, estados da matéria, ácidos e bases, densidade, ligações químicas, radioatividade, funções orgânicas e tópicos de Química Ambiental. Todos os artigos que tratavam da produção de HQs pelos alunos, de acordo com os níveis de ensino, para ambos os eventos, são apresentados no Quadro 2.

Quadro 2- Artigos da categoria MD que discutiam a produção de HQs pelos alunos.

\begin{tabular}{c|c|c|c|c} 
Evento & EF & EM & EJA & ES \\
\hline ENEQ & $8 \mathrm{MD}$ & $\begin{array}{c}1 \mathrm{MD}, 2 \mathrm{MD}, \\
5 \mathrm{MD}, 14 \mathrm{MD}, \\
20 \mathrm{MD}, 21 \mathrm{MD}, \\
24 \mathrm{MD}\end{array}$ & $18 \mathrm{MD}$ & 19MD, 25MD \\
\hline ENPEC & $\begin{array}{c}32 \mathrm{MD}, 36 \mathrm{MD}, \\
47 \mathrm{MD}\end{array}$ & $\begin{array}{c}35 \mathrm{MD}, 41 \mathrm{MD}, \\
45 \mathrm{MD}, 46 \mathrm{MD}, \\
50 \mathrm{MD}\end{array}$ & - & 39MD, 48MD \\
& \multicolumn{3}{|c|}{ Fonte: Autoria própria (201\&). } &
\end{tabular}

De maneira geral, as metodologias desses artigos contavam primeiro com uma etapa de desenvolvimento dos conteúdos em sala de aula, para que então, os alunos pudessem construir histórias em quadrinhos incorporando os conceitos aprendidos junto às suas próprias concepções, de modo que, com esse material, fosse possível avaliar todas as etapas do processo de ensino-aprendizagem.

Destaca-se aqui um dos artigos voltados para a Licenciatura, nos quas não é comum o desenvolvimento de atividades lúdicas para ensino, sobretudo nas disciplinas não pedagógicas. No artigo 19MD, é apresentado uma proposta de elaboração de relatórios científicos na forma de história em quadrinhos, na disciplina de Química Geral, por graduandos de um curso de Licenciatura em Química. Analisando a conclusão dos autores, percebeu-se que essa proposta de relatórios com formato de $\mathrm{HQ}$ possibilitou o desenvolvimento do pensamento criativo dos futuros docentes e facilitou a aprendizagem através de uma linguagem simples e dinâmica.

A outra metade dos artigos consistiu não na produção, mas na aplicação de HQs autorais ou previamente elaboradas por grupos de pesquisa em educação de instituições acadêmicas nacionais. Alguns desses artigos, também usou revistas e gibis populares, que mesmo tendo sido elaboradas fora do contexto pedagógico, apresentavam conceitos científicos que poderiam ser adaptados as salas de aula.

Em sua maioria, a metodologia dos artigos consistia na aplicação de uma $\mathrm{HQ}$ antes ou depois da abordagem de um novo conceito aos alunos, como no artigo 15MD, que utiliza a revista para avaliar as contribuições e/ou limitações das mesmas. Quase sempre os alunos respondiam a um questionário inicial e a um questionário final onde explicitavam os conceitos científicos aprendidos. Os artigos analisados que utilizaram essa metodologia, de acordo com seus respectivos níveis de ensino, são apresentados no Quadro 3. 
Quadro 3 - Artigos da categoria MD que discutiam uso de HQs previamente elaboradas.

\begin{tabular}{|c|c|c|c|c|c|}
\hline Evento & EF & EM & EJA & ES & 티 \\
\hline ENEQ & 17MD & $\begin{array}{c}7 \mathrm{MD}, 11 \mathrm{MD}, \\
12 \mathrm{MD}, 15 \mathrm{MD}, \\
16 \mathrm{MD}, 22 \mathrm{MD}, \\
23 \mathrm{MD}\end{array}$ & $6 \mathrm{MD}$ & $10 \mathrm{MD}$ & $3 \mathrm{MD}$ \\
\hline ENPEC & $\begin{array}{c}27 \mathrm{MD}, 30 \mathrm{MD}, \\
34 \mathrm{MD}, 37 \mathrm{MD}, \\
40 M D, 49 M D \\
51 \mathrm{MD}\end{array}$ & $\begin{array}{c}43 \mathrm{MD}, 52 \mathrm{MD}, \\
53 \mathrm{MD}\end{array}$ & - & - & - \\
\hline
\end{tabular}

Fonte: Autoria própria (2017).

Dentre esses artigos, destaca-se o artigo 3MD, que traz o relato do uso de uma $\mathrm{HQ}$ adaptada com texturas, para ensinar o conceito de átomo a alunos deficientes visuais. Para investigar o potencial do material os autores contaram com a avaliação do mesmo por um jovem que já conhecia o conceito de átomo da maneira como os livros didáticos abordam, já que sua perda de visão ocorreu após a conclusão do Ensino Médio Regular. Esse foi o único artigo encontrado que buscava o uso de histórias em quadrinhos como materiais para o Ensino Inclusivo, o que chama atenção para a baixa produção e a necessidade de avaliar as dificuldades em adaptar esse gênero para um público com necessidades especiais.

Sete artigos foram classificados na categoria ACE, como mostra o Quadro 4 abaixo. O critério de classificação desses artigos, deu-se pela utilização de metodologias específicas que permitiam uma análise mais aprofundada dos materiais, tais como análise textual discursiva, análise semiótica, análise de gêneros e funções atribuídas as histórias em quadrinhos, e análises qualitativas. Embora artigos como 39MD, 45MD, 46MD e 47MD, também fossem constituídos de análises dos materiais utilizados nas propostas, não foram considerados na categoria de artigos de análise por apresentarem um diagnóstico mais superficial, apenas na conclusão do trabalho, já que seu foco maior era avaliar a aprendizagem dos alunos e não o potencial didático dos materiais.

Quadro 4 - Artigos classificados na categoria ACE.

\begin{tabular}{c|c} 
Evento & Artigos \\
\hline ENEQ & 9ACE, 13ACE \\
\hline ENPEC & 28ACE, 33ACE, 38ACE, 42ACE, \\
& 54ACE.
\end{tabular}

Fonte: Autoria própria (2017).

Dessa categoria, quatro dos artigos fizeram análises do uso de HQs no ensino de Física (33ACE, 38ACE, 42ACE e 54ACE). Dentre esses, destacam-se dois artigos que analisaram as contribuições de duas revistas em quadrinhos específicas: a revista em quadrinhos Quarteto Fantástico Millenium, uma HQ de super-heróis voltada ao público jovem, distribuída no Brasil pela Editora Panini (artigo 33ACE), e uma revista da série Guia Mangá de Física, distribuída pela Editora Novatec, cujo intuito é ensinar conceitos técnicos e científicos, contextualizadas em meio as histórias em quadrinhos japonesas (artigo 42ACE). Ambos os artigos apresentam em suas conclusões, considerações extremamente favoráveis quanto as 
contribuições que esses materiais podem agregar ao processo ensino aprendizagem quando usados em sala de aula pelos professores, já que favorecem o processo de humanização da ciência.

O artigo 13ACE, consistiu na análise dos aspectos de divulgação científica presentes em tirinhas da Mafalda. Os autores avaliaram 9 tirinhas selecionadas do livro Toda Mafalda, que possui todas as tiras já publicadas sobre a personagem. A divulgação científica, em geral ocorria em meio a diálogos entre os personagens, sobre assuntos que os mesmos viam nos jornais ou ouviam nos rádios, o que permitiu aos autores, concluir que as tiras da Mafalda, por possuírem apelo crítico-social são bons instrumentos para fomentar discussões relativas a ciência em sala de aula, especialmente no que diz respeito a como a mídia coloca as informações para a sociedade, já que a simplicidade e sensacionalismo que jornais, revistas, e outros veículos de comunicação muitas vezes usam para propagar notícias limita o entendimento do público a respeito do assunto tratado.

O artigo 28ACE avaliou o potencial educativo trazido em histórias em quadrinhos do Maurício de Sousa, para temáticas ambientais. A escolha de analisar revistas da Maurício de Sousa Produções foi justificada no fato de as mesmas serem inteiramente produzidas no Brasil, o que confere a seus personagens, características do povo brasileiro, além de serem uma das revistas de maior tiragem e interesse por parte do público leitor infanto-juvenil no país.

Os autores analisaram qualitativamente os conteúdos relacionados à temática ambiental que fazem parte do enredo de algumas histórias em quadrinhos selecionadas, e sua importância enquanto difusoras de concepções e conceitos do campo das ciências ambientais. A análise pautou-se nas estratégias de linguagem (imagens, palavras e signos) utilizadas nas histórias, que, de acordo com eles, "podem ou não promover uma sensibilização ou conscientização do leitor sobre temáticas socioambientais, reveladas através das concepções que os personagens trazem de meio ambiente ou natureza". (LISBOA; JUNQUEIRA; DEL PINO, 2007, p. 1). Com a análise, os autores concluíram que, embora haja algumas contradições nas histórias de Mauricio de Sousa, já que nas histórias analisadas os conteúdos sejam tratados superficialmente, mostrando a visão dos personagens mas sem sugerir soluções para os problemas apresentados, isso não descaracteriza a possibilidade de uso desses materiais na educação ambiental informal, visto que as interpretações de cada história e dos conceitos nelas presentes, é individual a cada leitura e a cada leitor.

O artigo 9ACE analisou o potencial de uma revista de divulgação científica, que faz parte de uma série intitulada Sigma Pi, voltada para o ensino de Química. A metodologia utilizada pelos autores, consistiu em um questionário aplicado aos leitores da revista, por meio do qual foi possível conhecer o perfil dos mesmos e avaliar o aprendizado e interesses relacionados aos conteúdos apresentados pelas histórias. Os autores, ao avaliar esses questionários, concluíram que as HQs são ferramentas interessantes para o ensino não-formal de ciências, aliando entretenimento à informação, por meio de uma história cuja trama envolve conceitos de química e seja atraente ao público alvo. A respeito da revista analisada, eles ressaltaram que se trata de um bom material, já que, por ser um 
conteúdo como à forma de utilização em ambientes formais e não-formais de ensino.

Apenas três dos artigos encontrados mencionavam a necessidade de abordar sobre o uso de HQs como ferramentas didáticas em cursos de formação inicial e continuada, sendo que desses, um foi publicado no ENEQ (4FD) e dois foram publicados no ENPEC (29FD e 44FD). Dois dos artigos, falavam sobre a realização de atividades com alunos de cursos de licenciatura em Química (4FD) e Ciências Biológicas (44FD), onde eles mesmos desenvolviam as histórias em quadrinhos que poderiam vir a ser utilizadas como materiais didáticos em suas aulas. Pela análise dos artigos, percebe-se que, trabalhar com histórias em quadrinhos na formação inicial, dá subsídio para que os futuros docentes, ao estruturar suas aulas, saibam usar a seu favor a ludicidade trazida por esses materiais, mas sem perder o objetivo maior da discussão conceitual em sala.

O artigo 29FD discutia sobre uma atividade desenvolvida no processo formativo de dois professores de Ensino Fundamental, cujo objetivo era abordar alguns aspectos de História da Ciência por meio de uma história em quadrinhos, de modo que esses docentes viessem a utilizar esse recurso em suas aulas também. De acordo com os autores, a articulação promovida pelo uso dos quadrinhos nessa atividade formativa, possibilitou a reflexão na ação e sobre a ação dos docentes envolvidos, de modo que eles (re)significassem sua prática pedagógica, a partir de uma formação crítica e reflexiva, com recursos que também fazem parte da vivência dos alunos.

Dois artigos, um publicado no ENEQ (26LB) e um publicado no ENPEC (31LB), foram classificados na categoria LB, que, similar ao presente, voltaram seu foco aos estudos e trabalhos já realizados sobre o que e como se produz histórias em quadrinhos para o Ensino de Ciências.

$\mathrm{O}$ artigo 26LB analisa as produções sobre o uso de HQs no ensino publicadas no período de 2005 a 2015, nas revistas Química Nova na Escola, Ensenãnza de las Ciências, Revista Brasileira de Pesquisa em Educação em Ciências e Ciência \& Educação (Bauru), e também nos anais dos eventos Encontro Nacional de Ensino de Química (ENEQ) e Encontro Nacional de Pesquisa em Educação em Ciências (ENPEC), todos voltados a área de ensino de ciências, priorizando-se os trabalhos voltados ao ensino de Química. Os autores, encontraram nove artigos, utilizando em suas buscas, as palavras-chave: Histórias em Quadrinhos, Ensino de Ciências e Ensino de Química, o que, de acordo com os mesmos, caracterizou em uma pequena produção de trabalhos sobre o ensino de HQs no ensino de ciências, sobretudo para o ensino de química.

Já o artigo 31LB caracteriza histórias em quadrinhos enquanto materiais didáticos de pesquisa e divulgação no ensino de ciências, partindo da análise de artigos publicados em periódicos nacionais e internacionais, dissertações e teses de programas de pós-graduação, afim de investigar como a elaboração de metodologias que utilizem HQs, podem contribuir para uma prática científica reflexiva em professores e alunos. Com o estudo, os autores concluíram que é fundamental que pesquisas acadêmicas com histórias em quadrinhos, apresentem entre outras coisas, sugestões para elaboração de metodologias que utilizem HQs que priorizem a reflexão em Ciência e elevem a percepção dos alunos para além do humor e do entretenimento, já que esses materiais consistem em apenas uma das várias formas de divulgação que influenciam no 
modo como os alunos concebem a ciência, cabendo ao professor orientá-los a distinguir as informações coerentes das equivocadas.

\section{CONCLUSÃO}

Com esse levantamento bibliográfico, percebeu-se uma tendência nos trabalhos analisados em produzir de histórias em quadrinhos inéditas para uso didático. De maneira menos expressiva, alguns trabalhos pautam-se no uso de histórias derivadas de revistas populares e que não foram criadas necessariamente com o intuito de atuarem na divulgação científica, mas que também podem fomentar discussões nos mais diversos níveis de ensino. Contudo, há também, uma carência de estudos que se propõem a analisar como os conceitos e concepções de ciência presentes nesses materiais já existentes afetam o processo de ensinoaprendizagem dos que com eles tem contato.

Por esse motivo, os passos seguintes de nossa pesquisa envolvendo histórias em quadrinhos, serão guiados por uma análise voltada à forma e ao contexto em que as HQs inserem o homem enquanto produtor da ciência e a ciência enquanto produto pronto e até que ponto isso se afasta da realidade e influencia o imaginário popular dos leitores adeptos a esse gênero.

Não menos importante, esse levantamento bibliográfico, também nos permitiu conhecer melhor como histórias em quadrinhos se consolidaram ao longo do tempo, enquanto meios de divulgação científica em ambientes formais, informais e não formais de ensino, possibilitando o surgimento de novas estratégias no que diz respeito ao ensino de ciências.

Embora acreditemos que existam muitos outros artigos que discutam HQs no ensino de ciências, publicadas em outros eventos e periódicos não utilizados em nosso levantamento, percebemos um aumento significativo de produções desse tipo especialmente nos últimos 5 anos, já que, cerca de $70 \%$ dos artigos que compõem nossa pesquisa, foram publicados nesse período. Entender o que está levando as HQs a se tornarem um dos focos de pesquisas na área de ensino atualmente, pode vir a ser alvo de estudos futuros, mas é algo que, por hora, foge de nosso escopo. 


\title{
Comics in science teaching: a look at what was produced in the last 12 years in ENEQ and ENPEC
}

\begin{abstract}
This paper presents an overview on how the comics are addressed in the context of Brazilian science education. Starting from a bibliographical survey in two major events in field of science education, the works were divided into categories and grouped according to the main focus of its studies. Most of the papers that make up our Bibliographical Research have focused on the use of Comics as teaching materials for teaching science in the elementary school, and also to the teaching of chemistry in high school. Some of the works obtained, highlighting the contributions that some comic books or manifestations of gender in textbooks, they bring to the teaching of science. A small portion of the papers analyzed discuss the comics in teacher education. In the last 5 years, there has been a significant increase in productions aimed at use and the contributions of Comics in science education. Studies that discuss about the use of unpublished materials appear more frequently when compared those who propose the analysis and/or use of materials already available.
\end{abstract}

KEYWORDS: Comics. Science teaching. Bibliographical survey. 


\section{REFERÊNCIAS DOS ARTIGOS ANALISADOS}

\begin{tabular}{|c|c|}
\hline Código & Artigo \\
\hline $1 \mathrm{MD}$ & $\begin{array}{l}\text { SANTOS, A.F. et al. Proposta de uma aprendizagem divertida através da } \\
\text { construção de histórias em quadrinhos. In: Encontro Nacional de Ensino } \\
\text { de Química, n. XIV, 2008, Curitiba. Anais do XIV Encontro Nacional de } \\
\text { Ensino de Química. Curitiba: Sociedade Brasileira de Química, 2008. p. } \\
\text { 1. }\end{array}$ \\
\hline $2 \mathrm{MD}$ & $\begin{array}{l}\text { ARAUJO, G. R.M.; NEGRAO F.C.; SILVA L.P. O uso de histórias em } \\
\text { quadrinhos como metodologia alternativa para o ensino de ligações } \\
\text { iônicas. In: Encontro Nacional de Ensino de Química, n. XV, 2010, } \\
\text { Brasília. Anais do XV Encontro Nacional de Ensino de Química. Brasília: } \\
\text { Sociedade Brasileira de Química, 2010. p. } 1 \text {. }\end{array}$ \\
\hline $3 \mathrm{MD}$ & $\begin{array}{l}\text { OLIVEIRA, R. V. D. L.; DELOU, C. M. C.; CORTES, C. E. S. O ensino de } \\
\text { estrutura atômica utilizando uma história em quadrinhos inclusiva. In: } \\
\text { Encontro Nacional de Ensino de Química, n. XV, 2010, Brasília. Anais do } \\
\text { XV Encontro Nacional de Ensino de Química. Brasília: Sociedade } \\
\text { Brasileira de Química, 2010. p. 1. }\end{array}$ \\
\hline 4ACE & $\begin{array}{l}\text { BORGES, C.D. et al. Uso das Tecnologias da Informação e Comunicação } \\
\text { para produção de Histórias em Quadrinhos no contexto da formação de } \\
\text { professores de Química. In: Encontro Nacional de Ensino de Química, n. } \\
\text { XV, 2010, Brasília. Anais do XV Encontro Nacional de Ensino de } \\
\text { Química. Brasília: Sociedade Brasileira de Química, 2010. p. 1. }\end{array}$ \\
\hline $5 \mathrm{MD}$ & $\begin{array}{l}\text { SANTOS, P. N.; AQUINO, K. A. S. Produção de Histórias em Quadrinhos } \\
\text { no Ensino de Química Orgânica: A Química dos Perfumes como } \\
\text { Temática. In: Encontro Nacional de Ensino de Química, n. XV, 2010, } \\
\text { Brasília. Anais do XV Encontro Nacional de Ensino de Química. Brasília: } \\
\text { Sociedade Brasileira de Química, 2010. p. 1-8. }\end{array}$ \\
\hline $6 \mathrm{MD}$ & $\begin{array}{l}\text { SANTOS, D. O.; LIMA, J. P. M.; FILHO, J. C. S. A Química do Ovo: Uma HQ } \\
\text { para o Ensino de Química. In: Encontro Nacional de Ensino de Química, } \\
\text { n. XV, 2010, Brasília. Anais do XV Encontro Nacional de Ensino de } \\
\text { Química. Brasília: Sociedade Brasileira de Química, 2010. p. 1. }\end{array}$ \\
\hline $7 \mathrm{MD}$ & $\begin{array}{l}\text { UCHOA, A. M.; JUNIOR, W. E. F.; FRANCISCO, W. Produção e avaliação } \\
\text { de uma história em quadrinhos para o ensino de Química. In: Encontro } \\
\text { Nacional de Ensino de Química, n. XVI, 2012, Salvador. Anais do XVI } \\
\text { Encontro Nacional de Ensino de Química. Salvador: Sociedade } \\
\text { Brasileira de Química, 2012. p. 1-12. }\end{array}$ \\
\hline $8 \mathrm{MD}$ & $\begin{array}{l}\text { SANTOS, G. Histórias em Quadrinhos: Uma proposta de aprendizagem } \\
\text { lúdica com alunos do 9o ano nas aulas de Química. In: Encontro } \\
\text { Nacional de Ensino de Química, n. XVI, 2012, Salvador. Anais do XVI } \\
\text { Encontro Nacional de Ensino de Química. Salvador: Sociedade } \\
\text { Brasileira de Química, 2012. p. 1. }\end{array}$ \\
\hline $9 A C E$ & $\begin{array}{l}\text { IWATA, A. Y.; LUPETTI, K. O.; MOURA, A. F. Sigma Pi: Quadrinhos para } \\
\text { divulgação e ensino de ciências. In: Encontro Nacional de Ensino de } \\
\text { Química, n. XVI, 2012, Salvador. Anais do XVI Encontro Nacional de } \\
\text { Ensino de Química. Salvador: Sociedade Brasileira de Química, 2012. p. } \\
\text { 1. }\end{array}$ \\
\hline $10 \mathrm{ML}$ & $\begin{array}{l}\text { GAMA, E. J. S.; JUNIOR, W. E. F. Avaliando uma história em quadrinhos } \\
\text { produzida para o ensino de química e educação ambiental. In: Encontro } \\
\text { Nacional de Ensino de Química, n. XVII, 2014, Ouro Preto. Anais do XVII }\end{array}$ \\
\hline
\end{tabular}




\begin{tabular}{|c|c|}
\hline Código & Artigo \\
\hline & $\begin{array}{l}\text { Encontro Nacional de Ensino de Química. Ouro Preto: Sociedade } \\
\text { Brasileira de Química, 2014. p. 1-11. }\end{array}$ \\
\hline $11 \mathrm{MD}$ & $\begin{array}{l}\text { SANTOS, J. S. Abordagem do comportamento ácido e básico nas frutas } \\
\text { através das Histórias em Quadrinhos (HQs). In: Encontro Nacional de } \\
\text { Ensino de Química, n. XVII, 2014, Ouro Preto. Anais do XVII Encontro } \\
\text { Nacional de Ensino de Química. Ouro Preto: Sociedade Brasileira de } \\
\text { Química, 2014. p. 1-11. }\end{array}$ \\
\hline $12 \mathrm{MD}$ & $\begin{array}{l}\text { RODRIGUES, A. A. D.; QUADROS, A. L. O uso de Histórias em Quadrinhos } \\
\text { no Ensino de Química: relatando uma experiência. In: Encontro } \\
\text { Nacional de Ensino de Química, n. XVII, 2014, Ouro Preto. Anais do XVII } \\
\text { Encontro Nacional de Ensino de Química. Ouro Preto: Sociedade } \\
\text { Brasileira de Química, 2014. p. 1-9. }\end{array}$ \\
\hline 13ACE & $\begin{array}{l}\text { FIORESI, C. A.; CUNHA, M. B. Mafalda e a Divulgação da Ciência. In: } \\
\text { Encontro Nacional de Ensino de Química, n. XVII, 2014, Ouro Preto. } \\
\text { Anais do XVII Encontro Nacional de Ensino de Química. Ouro Preto: } \\
\text { Sociedade Brasileira de Química, 2014. p. 1-9. }\end{array}$ \\
\hline $14 \mathrm{MD}$ & $\begin{array}{l}\text { SOUSA, B. A. et al. Vencendo os obstáculos do ensino de química } \\
\text { através de histórias em quadrinhos da Tabela Periódica dos Elementos. } \\
\text { In: Encontro Nacional de Ensino de Química, n. XVII, 2014, Ouro Preto. } \\
\text { Anais do XVII Encontro Nacional de Ensino de Química. Ouro Preto: } \\
\text { Sociedade Brasileira de Química, 2014. p. 1. }\end{array}$ \\
\hline $15 \mathrm{MD}$ & $\begin{array}{l}\text { SILVA, A. N. et al. Utilização de História em Quadrinhos na divulgação da } \\
\text { Nanotecnologia e suas aplicações. In: Encontro Nacional de Ensino de } \\
\text { Química, n. XVIII, 2016, Florianópolis. Anais do XVIII Encontro Nacional } \\
\text { de Ensino de Química. Florianópolis: Sociedade Brasileira de Química, } \\
\text { 2016. p. 1. }\end{array}$ \\
\hline $16 \mathrm{MD}$ & $\begin{array}{l}\text { LOREDO, L. A. O uso de Histórias em Quadrinhos para a conscientização } \\
\text { de problemas de caráter social em escolas In: Encontro Nacional de } \\
\text { Ensino de Química, n. XVIII, 2016, Florianópolis. Anais do XVIII Encontro } \\
\text { Nacional de Ensino de Química. Florianópolis: Sociedade Brasileira de } \\
\text { Química, 2016. p. 1. }\end{array}$ \\
\hline $17 \mathrm{MD}$ & $\begin{array}{l}\text { SILVA, A. M.; SILVA, S. R. B. Nas teias dos elementos químicos: Ensino de } \\
\text { Química através dos quadrinhos. In: Encontro Nacional de Ensino de } \\
\text { Química, n. XVIII, 2016, Florianópolis. Anais do XVIII Encontro Nacional } \\
\text { de Ensino de Química. Florianópolis: Sociedade Brasileira de Química, } \\
\text { 2016. p. 1-11. }\end{array}$ \\
\hline $18 \mathrm{MD}$ & $\begin{array}{l}\text { POMBO, F. M. Z. et al. História em quadrinhos no ensino de Química na } \\
\text { EJA: uma proposta de recurso didático. In: Encontro Nacional de Ensino } \\
\text { de Química, n. XVIII, 2016, Florianópolis. Anais do XVIII Encontro } \\
\text { Nacional de Ensino de Química. Florianópolis: Sociedade Brasileira de } \\
\text { Química, 2016. p. 1-10. }\end{array}$ \\
\hline $19 \mathrm{MD}$ & $\begin{array}{l}\text { SOUSA, D. G.; SILVA, A. A. R.; OLIVEIRA, M. M. Relatório Experimental } \\
\text { baseado em quadrinhos (HQ's): uma nova proposta didática para } \\
\text { futuros docentes. In: Encontro Nacional de Ensino de Química, n. XVIII, } \\
\text { 2016, Florianópolis. Anais do XVIII Encontro Nacional de Ensino de } \\
\text { Química. Florianópolis: Sociedade Brasileira de Química, 2016. p. } 1 .\end{array}$ \\
\hline $20 \mathrm{MD}$ & $\begin{array}{l}\text { FIORESI, C. A.; CUNHA, M. B. Processo para elaboração de Histórias em } \\
\text { Quadrinhos: um estudo com estudantes do Ensino Médio. In: Encontro } \\
\text { Nacional de Ensino de Química, n. XVIII, 2016, Florianópolis. Anais do }\end{array}$ \\
\hline
\end{tabular}




\begin{tabular}{|c|c|}
\hline Código & Artigo \\
\hline & $\begin{array}{l}\text { XVIII Encontro Nacional de Ensino de Química. Florianópolis: } \\
\text { Sociedade Brasileira de Química, 2016. p. 1-11. }\end{array}$ \\
\hline $21 \mathrm{MD}$ & $\begin{array}{l}\text { SOUZA, J. A Química dos Oceanos como Temática para a } \\
\text { Contextualização. In: Encontro Nacional de Ensino de Química, n. XVIII, } \\
\text { 2016, Florianópolis. Anais do XVIII Encontro Nacional de Ensino de } \\
\text { Química. Florianópolis: Sociedade Brasileira de Química, 2016. p. } 1 .\end{array}$ \\
\hline $22 \mathrm{MD}$ & $\begin{array}{l}\text { MIGUEZ, L. S. Uma História em Quadrinhos - As Aventuras de Hélio em: } \\
\text { Estudando o Ciclo do Nitrogênio e o Princípio de Le Chatelier, In: } \\
\text { Encontro Nacional de Ensino de Química, n. XVIII, 2016, Florianópolis. } \\
\text { Anais do XVIII Encontro Nacional de Ensino de Química. Florianópolis: } \\
\text { Sociedade Brasileira de Química, 2016. p. 1-12. }\end{array}$ \\
\hline $23 \mathrm{MD}$ & $\begin{array}{l}\text { IWATA, A. Y.; RODRIGUES, A. C. M.; LUPETTI, K. O. Histórias de vidro em } \\
\text { quadrinhos: a divulgação científica em HQs. In: Encontro Nacional de } \\
\text { Ensino de Química, n. XVIII, 2016, Florianópolis. Anais do XVIII Encontro } \\
\text { Nacional de Ensino de Química. Florianópolis: Sociedade Brasileira de } \\
\text { Química, 2016. p. 1. }\end{array}$ \\
\hline $24 \mathrm{MD}$ & $\begin{array}{l}\text { AQUINO, A. Química em Quadrinhos! In: Encontro Nacional de Ensino } \\
\text { de Química, n. XVIII, 2016, Florianópolis. Anais do XVIII Encontro } \\
\text { Nacional de Ensino de Química. Florianópolis: Sociedade Brasileira de } \\
\text { Química, 2016. p. 1. }\end{array}$ \\
\hline $25 \mathrm{MD}$ & $\begin{array}{l}\text { REZENDE, F. A. M. Proposta de material didático em uma disciplina de } \\
\text { Pós-Graduação utilizando Histórias em Quadrinhos. In: Encontro } \\
\text { Nacional de Ensino de Química, n. XVIII, 2016, Florianópolis. Anais do } \\
\text { XVIII Encontro Nacional de Ensino de Química. Florianópolis: } \\
\text { Sociedade Brasileira de Química, 2016. p. 1. }\end{array}$ \\
\hline $26 \mathrm{LB}$ & $\begin{array}{l}\text { SANTOS, J. C.; SILVA, A. C. T.; OLIVEIRA, F. S. Histórias em Quadrinhos } \\
\text { no ensino de Química: o que tem sido produzido em revistas e eventos } \\
\text { da área na última década. In: Encontro Nacional de Ensino de Química, } \\
\text { n. XVIII, 2016, Florianópolis. Anais do XVIII Encontro Nacional de } \\
\text { Ensino de Química. Florianópolis: Sociedade Brasileira de Química, } \\
\text { 2016. p. 1-11. }\end{array}$ \\
\hline $27 \mathrm{MD}$ & $\begin{array}{l}\text { CABELLO, K. S.; MORAES, M.O. Educação e Divulgação Científica de } \\
\text { Hanseníase: Histórias em Quadrinhos para o Ensino da Doença. In: } \\
\text { Encontro Nacional de Pesquisa em Educação em Ciências, n. V, 2005, } \\
\text { Bauru. Anais do V Encontro Nacional de Pesquisa em Educação em } \\
\text { Ciências. Bauru: Associação Brasileira de Pesquisa em Educação em } \\
\text { Ciências, 2005. p. 1-11. }\end{array}$ \\
\hline $28 \mathrm{ACE}$ & $\begin{array}{l}\text { LISBOA, L. L.; JUNQUEIRA, H.; DEL PINO, J. C. A Temática Ambiental e } \\
\text { seu Potencial Educativo nas Histórias em Quadrinhos de Mauricio de } \\
\text { Souza. In: Encontro Nacional de Pesquisa em Educação em Ciências, n. } \\
\text { VI, 2007, Florianópolis. Anais do VI Encontro Nacional de Pesquisa em } \\
\text { Educação em Ciências. Florianópolis: Associação Brasileira de Pesquisa } \\
\text { em Educação em Ciências, 2007. p. 1-12. }\end{array}$ \\
\hline 29FD & $\begin{array}{l}\text { CARVALHO, L. S.; MARTINS, A. F. História da Ciência na Formação de } \\
\text { Professores das Séries Iniciais: Uma proposta com Quadrinhos. In: } \\
\text { Encontro Nacional de Pesquisa em Educação em Ciências, n. VII, 2009, } \\
\text { Florianópolis. Anais do VII Encontro Nacional de Pesquisa em Educação } \\
\text { em Ciências. Florianópolis: Associação Brasileira de Pesquisa em } \\
\text { Educação em Ciências, 2009. p. 1-12. }\end{array}$ \\
\hline
\end{tabular}




\begin{tabular}{|c|c|}
\hline Código & Artigo \\
\hline $30 \mathrm{MD}$ & $\begin{array}{l}\text { PIZARRO, M. V.; JUNIOR, J. L. A História em Quadrinhos como Recurso } \\
\text { Didático no Ensino de Indicadores da Alfabetização Científica nas Séries } \\
\text { Iniciais. In: Encontro Nacional de Pesquisa em Educação em Ciências, n. } \\
\text { VII, 2009, Florianópolis. Anais do VII Encontro Nacional de Pesquisa em } \\
\text { Educação em Ciências. Florianópolis: Associação Brasileira de Pesquisa } \\
\text { em Educação em Ciências, 2009. p. 1-11. }\end{array}$ \\
\hline $31 \mathrm{LB}$ & $\begin{array}{l}\text { PIZARRO, M. V. As Histórias em Quadrinhos como Linguagem e Recurso } \\
\text { Didático no Ensino de Ciências. In: Encontro Nacional de Pesquisa em } \\
\text { Educação em Ciências, n. VII, 2009, Florianópolis. Anais do VII Encontro } \\
\text { Nacional de Pesquisa em Educação em Ciências. Florianópolis: } \\
\text { Associação Brasileira de Pesquisa em Educação em Ciências, 2009. p. 1- } \\
12 .\end{array}$ \\
\hline $32 \mathrm{MD}$ & $\begin{array}{l}\text { MARTINS, E. K.; STADLER, R. C. L. O Ensino de Ciências e a utilização dos } \\
\text { gêneros textuais: A Transformação da fábula do Trypanosoma cruzi em } \\
\text { Histórias em Quadrinhos. In: Encontro Nacional de Pesquisa em } \\
\text { Educação em Ciências, n. VIII, 2011, Campinas. Anais do VIII Encontro } \\
\text { Nacional de Pesquisa em Educação em Ciências. Campinas: Associação } \\
\text { Brasileira de Pesquisa em Educação em Ciências, 2011. p. 1-12. }\end{array}$ \\
\hline $33 \mathrm{ACE}$ & $\begin{array}{l}\text { JUNIOR, F. A. N.; PIASSI, L. P. Um estudo sobre o potencial didático das } \\
\text { Histórias em Quadrinhos de Ficção Científica para o ensino de Física. In: } \\
\text { Encontro Nacional de Pesquisa em Educação em Ciências, n. VIII, 2011, } \\
\text { Campinas. Anais do VIII Encontro Nacional de Pesquisa em Educação } \\
\text { em Ciências. Campinas: Associação Brasileira de Pesquisa em Educação } \\
\text { em Ciências, 2011. p. 1-11. }\end{array}$ \\
\hline $34 \mathrm{MD}$ & $\begin{array}{l}\text { SILVA, M. D.; MATTA, B. N.; OLIVEIRA, R. R. Histórias em Quadrinhos } \\
\text { como metodologia alternativa na construção do conhecimento sobre } \\
\text { Poluição. In: Encontro Nacional de Pesquisa em Educação em Ciências, } \\
\text { n. VIII, 2011, Campinas. Anais do VIII Encontro Nacional de Pesquisa } \\
\text { em Educação em Ciências. Campinas: Associação Brasileira de Pesquisa } \\
\text { em Educação em Ciências, 2011. p. 1-12. }\end{array}$ \\
\hline $35 \mathrm{MD}$ & $\begin{array}{l}\text { MARTINS, B. A.; ROSA, P. R. S. Um estudo sobre a utilização de Histórias } \\
\text { em Quadrinhos criadas por alunos na superação das concepções } \\
\text { espontâneas em mecânica. In: Encontro Nacional de Pesquisa em } \\
\text { Educação em Ciências, n. VIII, 2011, Campinas. Anais do VIII Encontro } \\
\text { Nacional de Pesquisa em Educação em Ciências. Campinas: Associação } \\
\text { Brasileira de Pesquisa em Educação em Ciências, 2011. p. 1-12. }\end{array}$ \\
\hline $36 \mathrm{MD}$ & $\begin{array}{l}\text { SANTOS, T.C.; PEREIRA, E. G. C. Oficinas de Histórias em Quadrinhos } \\
\text { como instrumento de avaliação no Ensino de Ciências. In: Encontro } \\
\text { Nacional de Pesquisa em Educação em Ciências, n. VIII, 2011, Campinas. } \\
\text { Anais do VIII Encontro Nacional de Pesquisa em Educação em Ciências. } \\
\text { Campinas: Associação Brasileira de Pesquisa em Educação em Ciências, } \\
\text { 2011. p. 1-9. }\end{array}$ \\
\hline $37 \mathrm{M}$ & $\begin{array}{l}\text { PIZARRO, M. V.; IACHEL, G.; SANCHES, I. A. S. Discussões sobre a seleção } \\
\text { de lixo reciclável nos anos iniciais: uma proposta em alfabetização } \\
\text { científica a partir do trabalho com histórias em quadrinhos no 20 ano do } \\
\text { ensino fundamental. In: Encontro Nacional de Pesquisa em Educação } \\
\text { em Ciências, n. VIII, 2011, Campinas. Anais do VIII Encontro Nacional } \\
\text { de Pesquisa em Educação em Ciências. Campinas: Associação Brasileira } \\
\text { de Pesquisa em Educação em Ciências, 2011. p. 1-12. }\end{array}$ \\
\hline
\end{tabular}




\begin{tabular}{|c|c|}
\hline Código & Artigo \\
\hline $38 \mathrm{ACE}$ & $\begin{array}{l}\text { CALDAS, C. B. S.; LONDERO, L. Um estudo sobre o uso de História em } \\
\text { Quadrinhos em Coleções Didáticas de Física. In: Encontro Nacional de } \\
\text { Pesquisa em Educação em Ciências, n. IX, 2013, Águas de Lindóia. Anais } \\
\text { do IX Encontro Nacional de Pesquisa em Educação em Ciências. Águas } \\
\text { de Lindóia: Associação Brasileira de Pesquisa em Educação em Ciências, } \\
\text { 2013. p. 1-8. }\end{array}$ \\
\hline $39 \mathrm{MD}$ & $\begin{array}{l}\text { TELLEZ, I. R. A produção de história em quadrinhos a partir da leitura de } \\
\text { textos históricos por licenciandos do PIBID. In: Encontro Nacional de } \\
\text { Pesquisa em Educação em Ciências, n. IX, 2013, Águas de Lindóia. Anais } \\
\text { do IX Encontro Nacional de Pesquisa em Educação em Ciências. Águas } \\
\text { de Lindóia: Associação Brasileira de Pesquisa em Educação em Ciências, } \\
\text { 2013. p. 1-8. }\end{array}$ \\
\hline $40 M D$ & $\begin{array}{l}\text { TESTONI, L. A. et al. Histórias em Quadrinhos nas aulas de Física: uma } \\
\text { proposta de ensino baseada na enculturação científica. In: Encontro } \\
\text { Nacional de Pesquisa em Educação em Ciências, n. IX, 2013, Águas de } \\
\text { Lindóia. Anais do IX Encontro Nacional de Pesquisa em Educação em } \\
\text { Ciências. Águas de Lindóia: Associação Brasileira de Pesquisa em } \\
\text { Educação em Ciências, 2013. p. 1-8. }\end{array}$ \\
\hline $41 \mathrm{MD}$ & $\begin{array}{l}\text { SOUZA, E. O. R.; VIANNA, D. M. Reflexões sobre o uso de histórias em } \\
\text { quadrinhos para promover o discurso na aula. In: Encontro Nacional de } \\
\text { Pesquisa em Educação em Ciências, n. IX, 2013, Águas de Lindóia. Anais } \\
\text { do IX Encontro Nacional de Pesquisa em Educação em Ciências. Águas } \\
\text { de Lindóia: Associação Brasileira de Pesquisa em Educação em Ciências, } \\
\text { 2013. p. 1-8. }\end{array}$ \\
\hline $42 \mathrm{ACE}$ & $\begin{array}{l}\text { NETO, F. F. S.; PEREIRA, P. B.; SOUZA, C. A. Conceitos científicos nas } \\
\text { histórias em quadrinhos: possibilidades e desafios para um processo de } \\
\text { textualização. In: Encontro Nacional de Pesquisa em Educação em } \\
\text { Ciências, n. IX, 2013, Águas de Lindóia. Anais do IX Encontro Nacional } \\
\text { de Pesquisa em Educação em Ciências. Águas de Lindóia: Associação } \\
\text { Brasileira de Pesquisa em Educação em Ciências, 2013. p. 1-8. }\end{array}$ \\
\hline $43 \mathrm{MD}$ & $\begin{array}{l}\text { CRUZ, T. M. G. S.; MESQUITA, N. A. S.; SOARES, M. H. F. B. H'química - o } \\
\text { uso dos quadrinhos para o ensino de radioatividade. In: Encontro } \\
\text { Nacional de Pesquisa em Educação em Ciências, n. IX, 2013, Águas de } \\
\text { Lindóia. Anais do IX Encontro Nacional de Pesquisa em Educação em } \\
\text { Ciências. Águas de Lindóia: Associação Brasileira de Pesquisa em } \\
\text { Educação em Ciências, 2013. p. 1-7. }\end{array}$ \\
\hline $44 \mathrm{FD}$ & $\begin{array}{l}\text { FERNANDES, H. L.; GUERRA, V. T.; SAITO, R. M. Histórias em Quadrinhos } \\
\text { e Formação de Professores. In: Encontro Nacional de Pesquisa em } \\
\text { Educação em Ciências, n. IX, 2013, Águas de Lindóia. Anais do IX } \\
\text { Encontro Nacional de Pesquisa em Educação em Ciências. Águas de } \\
\text { Lindóia: Associação Brasileira de Pesquisa em Educação em Ciências, } \\
\text { 2013. p. 1-8. }\end{array}$ \\
\hline $45 \mathrm{MD}$ & $\begin{array}{l}\text { KUNDLATSCH, A.; MARQUES, C. A. Histórias em Quadrinhos no Ensino } \\
\text { de Química: análise da contribuição do desenho e da escrita para o } \\
\text { processo de ensino-aprendizagem. In: Encontro Nacional de Pesquisa } \\
\text { em Educação em Ciências, n. X, 2015, Águas de Lindóia. Anais do X } \\
\text { Encontro Nacional de Pesquisa em Educação em Ciências. Águas de }\end{array}$ \\
\hline
\end{tabular}




\begin{tabular}{|c|c|}
\hline ódigo & Artigo \\
\hline & $\begin{array}{l}\text { Lindóia: Associação Brasileira de Pesquisa em Educação em Ciências, } \\
\text { 2015. p. 1-8. }\end{array}$ \\
\hline $46 \mathrm{MD}$ & $\begin{array}{l}\text { IUWATA, A. Y.; LUPETTI, K. O. A Alfabetização científica em química por } \\
\text { meio das histórias em quadrinhos. In: Encontro Nacional de Pesquisa } \\
\text { em Educação em Ciências, n. X, 2015, Águas de Lindóia. Anais do X } \\
\text { Encontro Nacional de Pesquisa em Educação em Ciências. Águas de } \\
\text { Lindóia: Associação Brasileira de Pesquisa em Educação em Ciências, } \\
\text { 2015. p. 1-8. }\end{array}$ \\
\hline $47 \mathrm{MD}$ & $\begin{array}{l}\text { CAMPANINI, B. D.; ROCHA, M. B. Oficinas de histórias em quadrinhos } \\
\text { como recurso didático no Ensino de Ciências. In: Encontro Nacional de } \\
\text { Pesquisa em Educação em Ciências, n. X, 2015, Águas de Lindóia. Anais } \\
\text { do X Encontro Nacional de Pesquisa em Educação em Ciências. Águas } \\
\text { de Lindóia: Associação Brasileira de Pesquisa em Educação em Ciências, } \\
\text { 2015. p. 1-8. }\end{array}$ \\
\hline $48 \mathrm{MD}$ & $\begin{array}{l}\text { PEDREIRA, M. M.; OLIVEIRA, S. F.; GUIMARAES, M. N. K. Elaboração de } \\
\text { tirinhas de história em quadrinhos sobre o conceito de gene por } \\
\text { estudantes de Ensino Superior. In: Encontro Nacional de Pesquisa em } \\
\text { Educação em Ciências, n. X, 2015, Águas de Lindóia. Anais do X } \\
\text { Encontro Nacional de Pesquisa em Educação em Ciências. Águas de } \\
\text { Lindóia: Associação Brasileira de Pesquisa em Educação em Ciências, } \\
\text { 2015. p. 1-7. }\end{array}$ \\
\hline $49 \mathrm{MD}$ & $\begin{array}{l}\text { FERNANDES, L. H. et al. Dengue, escola e quadrinhos? In: Encontro } \\
\text { Nacional de Pesquisa em Educação em Ciências, n. X, 2015, Águas de } \\
\text { Lindóia. Anais do X Encontro Nacional de Pesquisa em Educação em } \\
\text { Ciências. Águas de Lindóia: Associação Brasileira de Pesquisa em } \\
\text { Educação em Ciências, 2015. p. 1-8. }\end{array}$ \\
\hline $50 \mathrm{MD}$ & $\begin{array}{l}\text { MIRANDA, A. C. G.; BRAIBANTE, M. E. F.; PAZINATO, M. S. Tema gerador } \\
\text { e produção de Histórias em quadrinhos: contribuições para } \\
\text { aprendizagem em Química e Biologia. In: Encontro Nacional de Pesquisa } \\
\text { em Educação em Ciências, n. X, 2015, Águas de Lindóia. Anais do X } \\
\text { Encontro Nacional de Pesquisa em Educação em Ciências. Águas de } \\
\text { Lindóia: Associação Brasileira de Pesquisa em Educação em Ciências, } \\
\text { 2015. p. 1-8. }\end{array}$ \\
\hline 51MD & $\begin{array}{l}\text { SANTOS, M. A. P.; OLIVEIRA, M. F. A.; MEIRELLES, R. M. S. A construção } \\
\text { da argumentação no ensino da alimentação: O uso de histórias em } \\
\text { quadrinhos. In: Encontro Nacional de Pesquisa em Educação em } \\
\text { Ciências, n. X, 2015, Águas de Lindóia. Anais do X Encontro Nacional de } \\
\text { Pesquisa em Educação em Ciências. Águas de Lindóia: Associação } \\
\text { Brasileira de Pesquisa em Educação em Ciências, 2015. p. 1-8. }\end{array}$ \\
\hline $52 \mathrm{MD}$ & $\begin{array}{l}\text { SOUZA, E. O. R.; VIANNA, D. M. Física em Quadrinhos: Um quadro n’o } \\
\text { bar no Folies-Bergère. In: Encontro Nacional de Pesquisa em Educação } \\
\text { em Ciências, n. X, 2015, Águas de Lindóia. Anais do X Encontro } \\
\text { Nacional de Pesquisa em Educação em Ciências. Águas de Lindóia: } \\
\text { Associação Brasileira de Pesquisa em Educação em Ciências, 2015. p. 1- } \\
\text { 8. }\end{array}$ \\
\hline 53MD & $\begin{array}{l}\text { FERNANDES, C. G. et al. O Uso de Histórias em Quadrinhos como } \\
\text { Estratégia Didática. In: Encontro Nacional de Pesquisa em Educação em } \\
\text { Ciências, n. X, 2015, Águas de Lindóia. Anais do X Encontro Nacional de }\end{array}$ \\
\hline
\end{tabular}




\begin{tabular}{l|l} 
Código & \multicolumn{1}{|c}{ Artigo } \\
\hline & $\begin{array}{l}\text { Pesquisa em Educação em Ciências. Águas de Lindóia: Associação } \\
\text { Brasileira de Pesquisa em Educação em Ciências, 2015. p. 1-8. }\end{array}$ \\
\hline \multirow{3}{*}{ 54ACE } & $\begin{array}{l}\text { VIEIRA, E. F.; HOSOUME, Y. Gêneros e Funções das Histórias em } \\
\text { Quadrinhos nos Livros Didáticos de Física - Das Décadas de } 1980 \text { a } \\
\text { 2010. In: Encontro Nacional de Pesquisa em Educação em Ciências, n. X, } \\
\text { 2015, Águas de Lindóia. Anais do X Encontro Nacional de Pesquisa em } \\
\text { Educação em Ciências. Águas de Lindóia: Associação Brasileira de } \\
\text { Pesquisa em Educação em Ciências, 2015. p. 1-8 }\end{array}$
\end{tabular}

\section{REFERÊNCIAS}

EISNER, W. Quadrinhos e arte sequencial. Tradução de Luís Carlos Borges. São Paulo: Martins Fontes, 1989.

KAMEL, C.; DE LA ROCQUE, L. As histórias em quadrinhos como linguagem fomentadora de reflexões-uma análise de coleções de livros didáticos de ciências naturais do ensino fundamental. Revista Brasileira de Pesquisa em Educação em Ciências, v. 6, n. 3, 2011.

LOVETRO, J. O. Origens das histórias em quadrinhos. In: TV Escola/Salto para o futuro. História em quadrinhos: um recurso de aprendizagem. Ano XXI, Boletim 01, abr. 2011, p. 10-14. Disponível em:<http://www.moodlelivre.com.br/images/stories/pdf_ppt_Doc/181213histor iaemquadrinhos.pdf>. Acesso em: 20 abr. 2017.

MIZUKAMI, M. G. N. Ensino: as abordagens do processo. Editora Pedagógica e Universitária, 1986.

MOYA, A. História da história em quadrinhos. Porto Alegre: L\&PM Editores S/A. 1986.

Recebido: 29 jul. 2017

Aprovado: 18 dez. 2017

DOI: $10.3895 /$ actio.v2n3.6818

Como citar:

CAMARGO, S. C.; RIVELINI-SILVA, A. C. Histórias em quadrinhos no ensino de ciências: um olhar sobre o que foi produzido nos últimos doze anos no ENEQ e ENPEC. ACTIO, Curitiba, v. 2, n. 3, p. 133-150,

out./dez. 2017. Disponível em: <https://periodicos.utfpr.edu.br/actio>. Acesso em: XXX.

Correspondência:

Susan Caroline Camargo

Rua Serra do Leão, 281 Bairro: Núcleo Habitacional Adriano Correia

86813-100 - Apucarana, Paraná, Brasil.

Direito autoral: Este artigo está licenciado sob os termos da Licença Creative Commons-Atribuição 4.0

Internacional. 